\title{
Smoking in Latin America: a major public health problem
}

\author{
Tabagismo na América Latina: \\ problema prioritário de saúde pública
}

Vera Luiza da Costa e Silva 1,2

Sergio Koifman 2

\footnotetext{
1 Coordenação Nacional de Controle de Tabagismo e Prevenção Primária de Câncer do Instituto Nacional de Câncer, Ministério da Saúde.

Rua dos Inválidos 212, $2 \underline{o}$ andar, Rio de Janeiro, $R J$ 20031-020, Brasil. costaesilva@inca.org.br 2 Departamento de Epidemiologia e Métodos Quantitativos em Saúde, Escola Nacional de Saúde Pública, Fundação Oswaldo Cruz.

Rua Leopoldo Bulhões 1480, Rio de Janeiro, $R J$ 21041-210, Brasil
}

\begin{abstract}
Smoking has become a major public health problem in Latin America, and its scope varies from country to country. Despite difficulties in obtaining methodologically consistent data for the region, we analyzed the results from prevalence surveys in 14 Latin American countries. Smoking prevalence among men varied from $24.1 \%$ (Paraguay) to $66.3 \%$ (Dominican Republic) and among women from 5.5\% (Paraguay) to 26,6\% (Uruguay). By applying point prevalence data to the stage model of the tobacco epidemic in developed countries, we concluded that the Latin American countries are in stage 2, i.e., with a clearly rising prevalence among men, a prevalence for women that is beginning to increase, and mortality attributable to smoking among men still not reflecting peak prevalence. None of the countries analyzed appeared to have reached stage 3, in which one observes a downward trend in prevalence of smoking among men and peak prevalence among women, with broad impact on tobacco-related mortality. The only exception appears to be Paraguay, which is still emerging from stage 1, i.e., with low prevalence rates among men, too. Nevertheless, high lung cancer mortality rates in Uruguay and Argentina are comparable to those of the developed countries.
\end{abstract}

Key words Smoking; Public Health; Prevalence; Impacts on Health; Mortality

Resumo O tabagismo já é um problema de saúde pública na América Latina, com dimensões variáveis de país para país. Foram analisados os resultados de inquéritos de prevalência em 14 países latino-americanos. A prevalência entre homens varia de 24,1\% (Paraguai) a 66,3\% (República Dominicana) e, entre as mulheres, de 5,5\% (Paraguai) a 26,6\% (Uruguai). Aplicandose dados pontuais de prevalência ao modelo de estágios da epidemia tabagística em países desenvolvidos, pode-se supor que todos os países latino-americanos estariam no estágio 2, ou seja, com a prevalência entre homens em franca elevação, prevalência entre mulheres iniciando crescimento e mortalidade atribuível ao tabagismo entre homens ainda não refletindo o pico de prevalência. Nenhum dos países analisados parece ter atingido o estágio 3, no qual se observa uma tendência à queda da prevalência de tabagismo entre homens e o pico de prevalência entre mulheres, com amplo impacto sobre a mortalidade tabaco-relacionada. A única exceção parece ser o Paraguai, que ainda se encontra saindo do nível 1,com taxas de prevalência baixas também entre homens. No entanto, elevadas taxas de mortalidade por câncer de pulmão são observadas no Uruguai e Argentina, apontando para a necessidade de priorizar o controle do tabagismo na região.

Palavras-chave Tabagismo; Saúde Pública; Prevalência; Impactos na Saúde; Mortalidade 


\section{Introduction}

Every ten minutes a person dies in the world as the result of tobacco use. In the early 1990s, three million deaths a year were caused by smoking, and this figure is increasing rapidly. If this trend is not reversed, 10 million deaths will occur by the year $2020,70 \%$ of which in the developing countries (WHO, 1997).

In most Latin America countries, health problems such as cholera, dengue, malaria, Hansen's disease, tuberculosis, and infectious diseases in general are still the main health problems for the population, focusing the attention of authorities in defining health policies. Although such problems have not been solved, these diseases have their public health approach guaranteed, with specific programs for their control in virtually all of the Latin American Ministries of Health. However, over the last three decades the Latin American countries have displayed major changes in their demographic, socioeconomic, and epidemiological profiles, thus raising the need to review the agenda of priorities for public health measures.

More and more people have emigrated to urban areas, the number of elderly people has increased, and the population as a whole is increasingly dying from causes related to life styles resulting from such changes (USDHHS, 1992). Among such life styles, tobacco use in its various forms, especially cigarette smoking, has become one of the main determinants of changes in this profile. Among such causes the most frequent are cardiovascular diseases and cancer, both of which are tobacco-related.

However, we are still focused exclusively on a public health approach for infectious diseases. The challenge for the next century is to also invest in the development of measures focusing on controlling risk factors for these diseases, thereby changing Latin America's morbidity and mortality profile.

Tobacco control must become a priority in public health programs (alongside vaccination and vector control programs) so that the growing invasion of transnational cigarette companies and their methods to induce the population to smoke will not catch these countries unprepared.

Factors fostering cigarette consumption should be controlled, like prices, smuggling, and absence of laws to regulate smoking. It is particularly important to create a favorable social context for not smoking, which can only be achieved by establishing a public health priority to check the growing cigarette consumption in the various Latin American countries.
Such factors must be identified, analyzed, and used by Latin American countries, which still lack information and fail to appreciate the impact of smoking on their respective populations. All knowledge pertaining to the dissemination of this risk factor should become the target of research, data collection, and epidemiological studies, crucial to the research agenda for these countries (Costa e Silva, 1995). Periodical, reliable, and comparable data on consumption and morbidity/mortality should allow the countries to measure the size and impact of tobacco use and are essential for obtaining a profile of this risk factor and evaluating the effectiveness of public health programs. Making such data available and accessible to health policy-making officials in the various countries should allow for a practical focus on the development of effective measures to control smoking.

\section{Methodology}

This article is intended to identify some of the most important topics in the epidemiology of smoking in Latin America, i.e., smoking prevalence, per capita consumption, and mortality from tobacco-related diseases in some of the Latin American countries with available data. We analyzed some aggregate data for the Americas as compared to other regions of the world (specifically compared to data from the United States and Canada) in order to situate Latin America in both the international context and that of the Americas.

\section{Prevalence}

Prevalence estimates for smoking are usually obtained from population surveys or surveys of given population groups. In general, the various surveys conducted in Latin America lack samples representative of their respective national populations; rather, they reflect cities, neighborhoods, or even smaller specific groups like health professionals, company employees, etc. In addition, data collection methodology varies, thus hampering comparative analyses among the various countries. Stratification by age bracket changes from one survey to the next, and even the definition of "smoker" varies: in some surveys it is limited to the question "Do you smoke?", thereby including regular and occasional smokers in the same category and leaving the characterization of such cigarette consumption up to the interviewee's subjective response (Robles, 1993). 
Nevertheless, systematically collected data from the World Health Organization on 16 countries of the Americas, including 14 from Latin America, were considered methodologically adequate, reliable, and comparable, although periodical studies had not been performed to allow for an analysis of trends over the years. These studies were representative of the respective national populations or a major segment thereof and have been used to construct global and regional estimates of smoking, representing $94 \%$ of the population of the Americas (WHO, 1997). The definition of a smoker only takes current cigarette consumption into account and does not specify whether use is occasional or daily. At any rate, minor differences in prevalence among countries may be due to the various sources of bias or other measurement errors. In virtually all cases, estimated prevalences should be considered approximate, due to problems of comparability and reliability.

\section{Per capita consumption}

Per capita consumption is a good indicator of current cigarette consumption, and by inference it indicates future tobacco-related morbidity and mortality.

Per capita consumption is obtained from the total cigarette consumption related to the consumer population over 15 years of age and is calculated based on cigarettes consumed (production plus importation minus exportation) divided by the population over 15 years of age. Per capita consumption is also subject to methodological problems. Smuggling and falsification of cigarettes are spreading in Latin America and hampering production of more precise data, thus serving as sources of error in countries like Brazil, Venezuela, Uruguay, and Argentina, into which cigarettes are smuggled mainly from Paraguay and Colombia (MS, 1998a). This underestimates consumption by country, since such data are gathered by the respective national tax-levying agencies, which only reflect legally sold cigarettes.

Another flaw in this indicator is its limited discriminatory power, since it is an aggregate measure and fails to evaluate consumption by different strata, i.e., by sex, age strata, or other specific population group.

\section{Mortality}

With regard to mortality data, despite the varying levels of underreporting and poorly defined cause of death in Latin American countries, data on mortality for the main tobaccorelated diseases are considered to have been obtained in regular fashion by most of the Latin American countries and are presented as mortality rates standardized per 100,000 inhabitants (number of deaths per given disease as related to population studied and standardized to the world population). WHO data from the early 1990s are analyzed; note that many changes in trends may have occurred in subsequent years.

\section{Results}

\section{Smoking prevalence}

Expansion of tobacco transnationals from the 1950s on and their focus on potential markets found fertile ground in Latin America, where four sociodemographic factors contributed to the growing number of potential smokers. These factors included growth in groups attracted to smoking ( $>15$ years of age) resulting from an increase in the population of adolescents and young adults; spread of urban life style (with heavy influence from American society); greater access to education, and entry of women into the labor market (USDHHS, 1992). Unlike the natural history of infectious diseases, where time from infection to clinical manifestation is short, health problems related to constant smoking show a greater time lag (MS, 1998b). As a consequence, depending on the specific disease, the mortality profile is determined basically by the consumption that occurred 20 or 30 years previously. This interval is the principal cause of our poor understanding of smoking's harmful effects. A model based on stages of the tobacco epidemic and allowing for an understanding of this process based on the experience of developed countries shows that certain information on smoking prevalence and its stratification by sex can be indicative of the real consequences still to be felt when the population has been fully exposed to cigarette consumption for a sufficient amount of time (Figure 1) (Lopez et al., 1994). If there is a comparable reduction in cigarette consumption, which can be achieved through a series of public health measures, these curves will have their slope attenuated, reaching lower peak prevalences for both males and fe- 


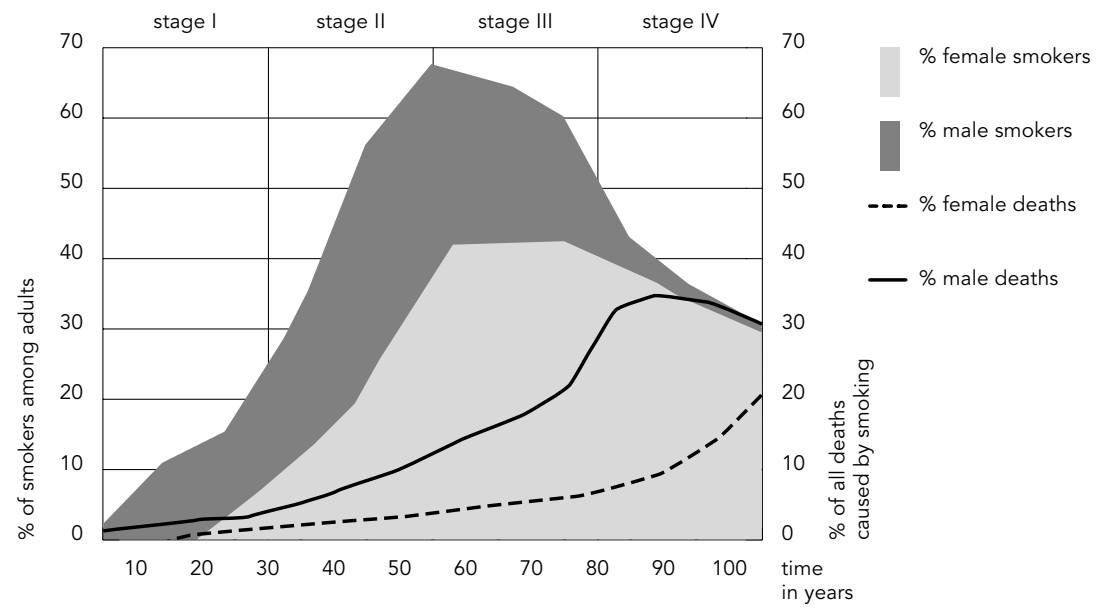

Source: Lopez et al., 1994.

males, with a resulting reduction in deaths from tobacco-related diseases 20 or 30 years later.

As we shall see later, some developing countries may already be in this situation, since they have not reached such high prevalence rates for male smokers as compared to developed countries and are already reducing their tobacco consumption in this population stratum, suggesting that mortality from tobacco-related diseases in 30 years will tend to decline, as long as the current reduction in consumption is maintained.

The characteristic of the tobacco epidemic in the developed countries as adapted to the four stages model is a sudden increase in the percentage of smokers among men, frequently involving $60-70 \%$ of the male population. In the two or three subsequent decades, deaths due to smoking among men begin to increase. The same pattern occurs later among women, because they typically reach a peak prevalence 15 to 20 years after men. Thirty years after reaching peak consumption among men, smoking can cause one third of all deaths among the latter or even more, up to 40 or $45 \%$ of deaths in middle-aged men.

Aggregate data by region for the WHO member countries show prevalence rates for the Americas as a whole as compared to other regions of the world (Table 1). Curiously enough, the region most comparable to the Americas in terms of prevalence is Europe, although ciga-
Table 1

Percentage of adult smokers (over 15 years of age) stratified by sex and region, early 1990s.

\begin{tabular}{lcc}
\hline Region & Men & Women \\
\hline Africa* & 29 & 4 \\
Americas & 35 & 22 \\
Eastern Mediterranean & 35 & 4 \\
Europe & 46 & 26 \\
Southeast Asia & 44 & 4 \\
Western Pacific & 60 & 8 \\
Developed countries & 42 & 24 \\
Developing countries & 47 & 12 \\
World & 47 & 12 \\
\hline
\end{tabular}

* Prevalence estimates for Africa are limited and should be used with caution.

Source: WHO, 1997

rette consumption by men is even heavier in the latter.

Based on this comparison, data aggregation for countries such as Canada, Uruguay, Brazil, Chile, and Cuba, where prevalence of smokers is high among women, appears to be reflected in the overall statistics for the Americas, where there are also countries in which relatively few women smoke (Table 2). Note that prevalence rates for smoking among men in the various regions of the world vary from as low as $29 \%$ (Africa) up to $60 \%$ (Western Pacific). When data 
are aggregated for developed as compared to developing countries, one observes different consumption "trends": in general men smoke more in the developing countries (stage 2) and women smoke more in developed countries (stage 3 ), suggesting in comparison to data from previous years that a decline in consumption is occurring among men in developed countries and that consumption is high among men in the developing countries, contrary to the situation for women, who smoke more in developed countries, thus displaying a different stage of cigarette consumption (Lopez et al., 1994). However, in some countries of the Americas we appear to be in an intermediate stage, with women steadily smoking more before men having reached prevalence rates as high as in the developed countries (late stage 2).

When prevalence data are broken down by sex among the countries of the Americas that were studied, the following major prevalence patterns stand out (Table 2).

The countries analyzed display prevalence rates for men ranging from $24.1 \%$ (Paraguay) to $66.3 \%$ (Dominican Republic). Rates for women vary from $5.5 \%$ (Paraguay) to $26.6 \%$ (Uruguay).

Applying only the point prevalence data by sex to the Lopez et al. (1994) model (since there are no available projections of tobacco-related deaths for the region) leads us to believe that Paraguay is the only Latin American country among those analyzed that might still be classified as stage 1 (with low prevalence rates for both men and women), warranting studies of historical series and sequential evaluations in order to monitor its potential entry into other stages.

In addition, we have both countries that are emerging from stage 1, like Paraguay, and beginning stage 2, like the Dominican Republic, Mexico, Honduras, Peru, and El Salvador. Meanwhile, Bolivia, Cuba, Uruguay, Argentina, Brazil, Chile, and Costa Rica, with similar prevalence patterns, have apparently still not reached stage 3 , in which deaths from tobacco-related diseases really reach major proportions, thus not allowing for the visibility of the public health problem that is still going to impact the Latin American continent. Still, these countries have prevalence rates for women that are sufficiently high to classify them in late stage 2 .

In virtually all of the Latin American countries analyzed except for Paraguay, men smoke more than in the United States and Canada, while in all of the countries analyzed women smoke less than in Canada and in 10 countries they smoke less than in the United States. Comparative prevalence studies should be per-
Table 2

Estimated prevalence of smoking, stratified by sex, for adults (> 15 years ), for selected countries of the Americas (most recent available data by sex)

\begin{tabular}{|c|c|c|c|c|}
\hline $\begin{array}{l}\text { Classification } \\
\text { for men }\end{array}$ & $\begin{array}{l}\text { Country } \\
\text { (year of survey) }\end{array}$ & Men & Women & $\begin{array}{l}\text { Classification } \\
\text { for women }\end{array}$ \\
\hline $1 \mathrm{st}$ & Dominican Rep. (1990) & 66.3 & 13.6 & 10th \\
\hline 2nd & Bolivia (1992) & 50 & 21.4 & 6th \\
\hline $3 r d$ & Cuba (1990) & 49.3 & 24.5 & 4 th \\
\hline 4 th & Peru (1989) & 41.0 & 13.0 & 11 th \\
\hline 5 th & Uruguay (1990 & 40.9 & 26.6 & $1 \mathrm{st}$ \\
\hline 6th & Argentina (1992) & 40.0 & 23.0 & 5 th \\
\hline 7 th & Brazil (1989) & 39.9 & 25.4 & $2 n d$ \\
\hline 8th & Mexico (1990) & 38.3 & 14.4 & 9th \\
\hline 9th & El Salvador (1988) & 38.0 & 12.0 & 12 th \\
\hline 10th & Chile (1990) & 37.9 & 25.1 & $3 r d$ \\
\hline 11th & Honduras (1988) & 36.0 & 11.0 & 12 th \\
\hline 12th & Colombia (1992) & 35.1 & 19.1 & 8th \\
\hline 13th & Costa Rica (1988) & 35.0 & 20.0 & 7 th \\
\hline 14th & Paraguay (1990) & 24.1 & 5.5 & 14 th \\
\hline $1 \mathrm{st}$ & Canada (1991) & 31.0 & 29.0 & $1 \mathrm{st}$ \\
\hline $2 n d$ & USA (1991) & 28.1 & 23.5 & 2nd \\
\hline
\end{tabular}

Source: WHO, 1997.

formed periodically in the region to evaluate consumption patterns and trends for Latin America, both among its own countries and with other countries and regions of the world. In addition, in order to adequately insert such research into the four stages model, proportions of deaths from tobacco-related diseases in historical series must be calculated.

The number of cigarettes smoked per day by habitual smokers for each WHO region shows that in general fewer cigarettes are smoked in the developing as compared to the developed countries (Table 3). Once again the Americas are comparable to Europe, and the consumption diversity for Latin America countries should be taken into account, along with the higher daily cigarette consumption in the United States and Canada, which increases the mean number of cigarettes smoked per day for the region as a whole.

\section{Per capita consumption}

Per capita cigarette consumption was stable for the European region, decreased in the Americas, and increased in other regions of the world. The developed countries reduced their consumption by $0.5 \%$, while global consumption increased by $0.8 \%$ due to increased consumption in the developing countries, which has 
Table 3

Number of cigarettes smoked per day by daily smokers, by WHO region.

\begin{tabular}{lc}
\hline Region & No of cigarettes/day \\
\hline Africa* & 10 \\
Americas & 18 \\
Eastern Mediterranean & 13 \\
Europe & 18 \\
Southeast Asia & 14 \\
Western Pacific & 16 \\
Developed countries & 22 \\
Developing countries & 14 \\
World & 15 \\
\hline
\end{tabular}

* Prevalence estimates for Africa are limited and should be used with caution.

Source: WHO, 1997

Table 4

Global and regional estimates and trends in per capita cigarette consumption for adults (>15 years), $1970-72$ to $1990-92$.

\begin{tabular}{lcccc}
\hline Region & $\begin{array}{c}1970-72 \\
(1)\end{array}$ & $\begin{array}{c}1980-82 \\
(2)\end{array}$ & $\begin{array}{c}1990-92 \\
(3)\end{array}$ & $\begin{array}{l}\text { \% annual } \\
\text { change from } \\
(1) \text { to (3) }\end{array}$ \\
\hline Africa & 460 & 570 & 590 & +1.2 \\
Americas & 2580 & 2510 & 1900 & -1.5 \\
Eastern Mediterranean & 700 & 940 & 930 & +1.4 \\
Europe & 2360 & 2500 & 2340 & 0.0 \\
Southeast Asia & 850 & 1140 & 1230 & +1.8 \\
Western Pacific & 1100 & 1610 & 2010 & +3.0 \\
Developed countries & 2860 & 2980 & 2590 & -0.5 \\
Developing countries & 860 & 1220 & 1410 & +2.5 \\
World & 1410 & 1650 & 1660 & +0.8 \\
\hline
\end{tabular}

Source: WHO, 1997. terns in Bolivia, Peru, and Guatemala, on a scale with countries from other developing regions.

However, as observed in the comparative per capita consumption for 1970-72 and 199092, none of the countries analyzed in Latin America has a higher per capita consumption than the developed countries (Table 5).

Thirteen countries in Latin America reduced their per capita consumption from 197072 to 1990-92, while 6 countries increased it. Added to the reduced per capita consumption during this period in the USA and Canada, this led to an overall reduction in per capita cigarette consumption in the Americas. These data suggest a downward trend in consumption for the region, albeit this should be evaluated with caution, given the limiting factors for analyzing per capita consumption. In addition, studies in Brazil on potential factors involved in varying cigarette consumption have pointed to the price of cigarettes, income, and public policies to restrict smoking (MS, 1998a). In Latin America, as a consequence of periodic losses in purchasing power, given the frequent economic crises, one observes short phases of reduction in consumption with real drops in consumption in some countries. This shows that public policies shall have a limited impact on variations in consumption, thus characterizing a major tobacco epidemic in the last 30 years (Rosemberg \& Costa e Silva, 1993). This also points to the need for systematic data collection on consumption, comparison with other countries, and an overall evaluation of determinant factors, especially economic ones.

Studies are needed in each Latin American country on factors related to cigarette prices and purchasing power, since these are the variables that tend to have a heavier impact on cigarette consumption. The reduction in consumption observed in Cuba, Colombia, Honduras, Peru, Guatemala, and other countries may be much more closely related to constant economic crises in these countries than to the implementation of effective tobacco control policies.

\section{Mortality from tobacco-related diseases} developing countries (1410 for 1990-92) (WHO, 1998).

Evaluation of per capita cigarette consumption in selected Latin American countries shows completely different profiles from country to country (Table 5). There are patterns similar to the developed countries, such as in $\mathrm{Cu}$ ba and Venezuela, with the highest consumption rates in the region over the last two decades, contrasting with consumption pat-
Thousands of studies a year corroborate the relationship between smoking and a whole series of diseases, a relationship that was proposed in studies initiated in the middle of this century (Doll \& Hill, 1950). Estimates of what this represents in terms of impact on worldwide mortality have been performed (Peto \& Lopez, 1994; Murray \& Lopez, 1997), reaching a total 
Estimated per capita cigarette consumption among adults (>15 years of age) from 1970-72 to 1990-92 in selected Latin American countries classified according to data for 1990-92.

\begin{tabular}{|c|c|c|c|c|c|}
\hline Classification & Country & $1970-72(1)$ & $1980-82(2)$ & $1990-92(3)$ & $\begin{array}{l}\% \text { change } \\
\text { from (1) to (3) }\end{array}$ \\
\hline $1 \mathrm{st}$ & Cuba & 2690 & 2630 & 2280 & -16 \\
\hline 2nd & Venezuela & 2060 & 2210 & 1920 & -7 \\
\hline $3 r d$ & Colombia & 1880 & 1790 & 1750 & -7 \\
\hline 4 th & Uruguay & 1630 & 1720 & 1700 & +4 \\
\hline 5 th & Argentina & 1810 & 1770 & 1610 & -11 \\
\hline 6th & Brazil & 1330 & 1750 & 1500 & +13 \\
\hline 7 th & Nicaragua & 1380 & 1440 & 1460 & +6 \\
\hline 8th & Costa Rica & 1850 & 1520 & 1340 & -28 \\
\hline 9th & Paraguay & 1190 & 1030 & 1100 & -8 \\
\hline 10th & Chile & 1310 & 1380 & 1030 & -22 \\
\hline 11 th & El Salvador & 1260 & 1030 & 1010 & -20 \\
\hline 12th & Dominican Rep. & 910 & 1010 & 1010 & +11 \\
\hline 13th & Mexico & 1600 & 1370 & 970 & -40 \\
\hline 14th & Panama & 1150 & 950 & 960 & -17 \\
\hline 15th & Ecuador & 650 & 830 & 870 & +33 \\
\hline 16th & Honduras & 1090 & 1080 & 850 & -22 \\
\hline 17th & Bolivia & 400 & 560 & 430 & +7 \\
\hline 18th & Peru & 410 & 390 & 350 & -15 \\
\hline 19th & Guatemala & 660 & 640 & 340 & -49 \\
\hline $1 \mathrm{st}$ & USA & 3700 & 3560 & 2670 & -28 \\
\hline $2 n d$ & Canada & 3910 & 3800 & 2540 & -36 \\
\hline $3 r d$ & Surinam & 1160 & 1870 & 1870 & +61 \\
\hline 4 th & Trinidad Tobago & 1440 & 1960 & 1780 & +24 \\
\hline 5 th & Guyana & 1220 & 1280 & 1130 & -39 \\
\hline 6th & Jamaica & 1400 & 990 & 860 & -39 \\
\hline 7th & Haiti & 170 & 630 & 580 & +215 \\
\hline
\end{tabular}

Source: WHO, 1997.

of 3.7 million deaths a year (estimated data for 1995). These estimates are based on the etiologic fraction of smoking in diseases caused by tobacco consumption. The etiologic fraction is calculated based on the estimated relative risk of a given disease and varies according to the prevalence of exposure to tobacco use and is applied to the mortality for the respective tobacco-related disease. Since in Latin America the relative risks for tobacco-related diseases have scarcely been studied (with regard to the proportion of mortality from the main diseases attributable to smoking), estimates have been performed based on approximations with data from developed countries. Based on these, in well-established market economies, where tobacco use was higher three or four decades ago, they account for a large number of such deaths, a reality which tends to decline, since there is a gradual reduction in consumption in this group of developed countries (Table 6) (WHO, 1997). Asia, particularly including China, and Northern Africa represent $43 \%$ of these total deaths, indicating the challenge of controlling smoking in this region, which has been invaded steadily by transnational tobacco companies. The countries from the former socialist bloc have a high prevalence of smokers and lack effective preventive measures, already displaying alarmingly high tobacco-related mortality rates. Latin America and the Caribbean already total 135,000 deaths, followed by Sub-Saharan Africa in the number of deaths from tobacco-related diseases (Table 6). Studies measuring the impact of smoking on mortality in the developing countries should be a priority, since estimates for regions like Latin America are only approximate and probably underestimate the real situation (USDHHS, 1992). 
Table 6

Estimated number of deaths caused by smoking in 1995, by region

\begin{tabular}{|c|c|c|c|}
\hline Region & Men & Women & Total \\
\hline Developed countries & 1440000 & 475000 & 1915000 \\
\hline Established market economies & 840000 & 375000 & 1215000 \\
\hline Former European socialist economies & 600000 & 100000 & 700000 \\
\hline Developing countries & 1620000 & 250000 & 1870000 \\
\hline China & 925000 & 175000 & 1100000 \\
\hline Asia and Northern Africa & 500000 & 40000 & 540000 \\
\hline Sub-Saharan Africa & 90000 & 5000 & 95000 \\
\hline Latin America and Caribbean & 105000 & 30000 & 135000 \\
\hline World & 3060000 & 725000 & 3785000 \\
\hline
\end{tabular}

Source: WHO, 1997.

Table 7

Annual mortality rate standardized by age per 100,000 inhabitants (early 1990) in selected countries of the Americas.

\begin{tabular}{|c|c|c|c|c|c|c|c|}
\hline Country & & $I C D$ & CVD & COPD & Lung cancer & All cancers & All causes \\
\hline \multirow[t]{2}{*}{ Argentina } & Men & 127.8 & 119.1 & 16.6 & 55.9 & 229.8 & 1230.4 \\
\hline & Women & 60.4 & 85.0 & 6.3 & 8.9 & 141.2 & 744.5 \\
\hline \multirow[t]{2}{*}{ Chile } & Men & 146.4 & 115.7 & 41.1 & 31.8 & 215.6 & 1236.8 \\
\hline & Women & 89.5 & 91.5 & 18.7 & 9.0 & 166.8 & 790.6 \\
\hline \multirow[t]{2}{*}{ Mexico } & Men & 118.1 & 66.7 & NA & 24.4 & 124.7 & 1135.4 \\
\hline & Women & 77.6 & 61.3 & NA & 9.0 & 113.3 & 796.4 \\
\hline \multirow[t]{2}{*}{ Panama } & Men & 132.4 & 103.6 & NA & 22.9 & 134.7 & 918.6 \\
\hline & Women & 102.4 & 93.2 & NA & 7.3 & 109.2 & 686.7 \\
\hline \multirow[t]{2}{*}{ Uruguay } & Men & 166.8 & 124.2 & NA & 82.9 & 309.4 & 1263.9 \\
\hline & Women & 84.7 & 100.3 & NA & 6.2 & 164.1 & 721.4 \\
\hline \multirow[t]{2}{*}{ Venezuela } & Men & 163.7 & 88.1 & NA & 24.3 & 139.0 & 1146.5 \\
\hline & Women & 107.1 & 82.2 & NA & 10.9 & 122.2 & 835.5 \\
\hline \multirow[t]{2}{*}{ Canada } & Men & 213.7 & 53.6 & 44,9 & 82.9 & 253.5 & 900.9 \\
\hline & Women & 107.4 & 44.4 & 16,6 & 31.5 & 161.3 & 533.7 \\
\hline \multirow[t]{2}{*}{ USA } & Men & 235.5 & 52.8 & 45,3 & 85.9 & 251.7 & 1021.7 \\
\hline & Women & 126.4 & 46.2 & 23,6 & 36.9 & 163.4 & 616.8 \\
\hline
\end{tabular}

$\mathrm{NA}=$ not available; $I C D=$ ischemic coronary disease $; C V D=$ cardiovascular diseases;

COPD = chronic obstructive pulmonary disease

Source: WHO, 1998. 
Lung cancer has been used as an indicator of a population's exposure to tobacco use. The relationship between the mortality rate in given countries and the highest mortality rate from lung cancer reached by the United States was described as an index of maturity in the tobacco epidemic for the respective country (USDHHS, 1992). In Latin America, by observing mortality rates from tobacco-related diseases (Table 7), one observes that the countries that probably had the highest prevalence of smokers two to three decades ago have the highest mortality rates from lung cancer now, e.g., mortality rates for men in Argentina and Uruguay, the latter displaying rates comparable to those of the United States for the same study period. However, mortality rates for other tobacco-related causes are comparably lower, probably due to other intervening causal factors such as non-comparable diet factors, hipertension etc.

Another datum displaying different impact for lung cancer is its mortality rate among women, reflecting a lower rate of exposure to smoking among this group in the last 30 years.

Also noteworthy is the high incidence of cerebrovascular diseases in the Latin American countries analyzed in this study as compared to the United States and Canada, which can be attributed to control of risk factors like hypertension and hypercholesterolemia in more developed societies.

At any rate, systematic analysis of mortality from tobacco-related diseases, i.e., mortality attributable to smoking, should be a central part of a tobacco epidemic surveillance system.

\section{Conclusions}

Latin America is heterogeneous with regard to tobacco use, determinant factors for consumption, the impact caused by smoking on its mortality profile, and prioritization of control measures and lines of research. A survey of data for all Latin American countries showed that in most of them smoking still appears to be socially acceptable (PAHO, 1992). Meanwhile, transnational cigarette companies have smothered the continent with countless advertising campaigns, expanding their markets and imposing tobacco consumption at every turn. Little has been studied or described on smoking in Latin America and its impact on contemporary Latin American societies. Nevertheless, the available data are sufficient to show that epidemiological studies on the impact of smoking on the morbidity and mortality profiles in each of these countries must be included in the public health research agenda. Systematic prevalence data must be collected to alert us to consumption trends. Determinant behavioral, economic, and social factors in cigarette consumption must be studied in order for this set of data to orient public health policies and measures in this area. All such information must be part of a data surveillance system on smoking, a priority in the implementation, monitoring, and evaluation of national tobacco control programs.

\section{Acknowledgements}

We thank Valeska Figueiredo and Silvana Rubano Turci for reviewing this article and making pertinent comments and suggestions.

\section{References}

COSTA E SILVA, V. L., 1995. Tobacco as a serious threat to Latin American Development. Presented at Bellagio Conference: Recommendations on tobacco use and sustainable development. Bellagio: Bellagio Conference.

DOLL, R. \& HILL, A. B., 1950. Smoking and Carcinoma of the lung. Prelimary report. British Medical Journal (30/9) ii:739-748.

LOPEZ, A. D.; COLLISHAW, N. \& PIHA, T., 1994. A descriptive model of the cigarette epidemic in developed countries. Tobacco Control, an International Journal, 3:242-247. 
MS (Ministério da Saúde), 1998a. Economia do Tabaco no Brasil. Rio de Janeiro: Instituto Nacional de Câncer, Coordenação Nacional de Controle do Tabagismo e Prevenção de Câncer.

MS (Ministério da Saúde), 1998b. Falando sobre Tabagismo. Rio de Janeiro: Instituto Nacional do Câncer, Coordenação Nacional de Controle do Tabagismo e Prevenção do Câncer.

MURRAY, C. I. L. \& LOPEZ, A. D., 1997. Quantifying Global Health Risks Estimates of the Burden of Disease Attributable to Select Risk Factors. Cambridge: Harvard University Press.

PAHO (Pan-American Health Organization), 1992. Tobacco or Health: status in the Americas: A Report of the Pan-American Health Organization. Scientific Publication no 536. Washington, D.C.: Pan American Health Organization.

PETO, R. \& LOPEZ, A. D., 1994. Mortality from smoking in developed countries, 1950-2000. Oxford: Oxford University Press.
ROBLES, S. C., 1993. Smoking among women in the Americas. In: Genero, Mujer y Salud (E. G. Goméz, ed.), pp. 163-170. Washington, D.C.: Pan-American Health Organization Scientific Publication no 541.

ROSEMBERG, J. \& COSTA E SILVA, V. L., 1993. Politica y estrategias para el controle de la epidemia del tabaquismo en America Latina. Boletín CLACCTA, 20:4-5.

USDHHS (United States Department of Health and Human Services), 1992. Smoking and Health in the Americas. Atlanta, Georgia: AHHS (Publication no (CDC) 92-8419).

WHO (World Health Organization), 1997. Tobacco or Health: First Global Status Report. Geneva: Tobacco or Health Programme/WHO.

WHO (World Health Organization), 1998. Guidelines for Controlling and Monitoring the Tobacco Epidemic. Geneva: WHO. 